\title{
SERVIÇO DE RECUPERAÇÃO DA INFORMAÇÃO NA BIBLIOTECA DE UM LABORATÓRIO FARMACÊUTICO - UM ESTUDO PRÁTICO
}

ROBSON DA SILVA TEIXEIRA

\section{Resumo:}

Descreve um estudo de usuários visando identificar qual a relação entre o usuário e o Serviço de Recuperação da Informação (SRI) da Biblioteca de uma indústria farmacêutica, estabelecendo uma metodologia para verificação de perfis de usuários potenciais. Um questionário com 22 perguntas foi aplicado a 70 colaboradores, obtendo-se um retorno de 36 questionários, $51,4 \%$ da amostragem. Os resultados revelaram que a relação entre os usuários e o SRI está na faixa entre bom e ótimo.

\section{Palavras-chave:}

Estudo de usuários; Serviço de recuperação da informação

\section{REPORTING AN EXPERIENCE: A STUDY TO IDENTIFY THE RELATIONSHIP BETWEEN USER AND INFORMATION SERVICE RETRIEVAL OF A PHARMACY LABORATORY LIBRARY}

\begin{abstract}
:
Describes a study of users aiming at identify relationship between user and Information Retrieval Service of a Pharmacy Laboratory Library, establishing a methodology for verification of potential user profile. A twenty-two questions questionnaire was applied to seventy people, out of that thirty-six questionnaire returned, 51,4\% percent of the sample. The results lead to the conclusion that the relationship between user ande Service Retrieval Information is good or excellent.
\end{abstract}

Keyword:

Study of user; Information retrieval service 


\section{INTRODUÇÃO}

O cenário atual demonstra o alto grau de decisões que devem ser tomadas como forma de colocar uma empresa em padrão de eficiência e eficácia em suas atividades, por isso, uma avaliação dos serviços oferecidos pelo Serviço de Recuperação da Informação da Biblioteca de uma indústria farmacêutica, torna-se necessário para uma melhor compreensão das necessidades informacionais de seus usuários pois poderá refletir em modificações no serviço em função das necessidades identificadas.

O volume de informações geradas e consumidas vêm aumentando aceleradamente, o que torna a Tecnologia da Informação uma das principais ferramentas a serem utilizadas para obtenção de ganhos de qualidade e produtividade, considerando sua rapidez e confiabilidade. Neste contexto, o Serviço de Recuperação da Informação (SRI) deve atender às necessidades específicas dos usuários, permitindo ao máximo o acesso a informações relevantes. Com a necessidade de colocar a informação ao alcance dos médicos, quando e onde for necessário e, aliado ao fato do aumento do volume de publicações na área médica, o Serviço de Informação da Biblioteca do Laboratório Knoll, tornou-se indispensável para gerenciar, disseminar e recuperar toda informação solicitada em tempo hábil.

Este estudo avaliará os serviços e produtos, bem como o grau de satisfação do usuário com o serviço e o que poderá ser mudado ou reavaliado em função de uma melhor adequação às necessidades destes usuários.

De modo geral, os estudos de usuários vêm sendo aplicados a usuários reais das bibliotecas ou objetivam, de modo sublinear, ratificar atividades, projetos, serviços, justificando a aplicação de recursos. 


\section{SERVIÇO DE RECUPERAÇÃO DA INFORMAÇÃO NO LABORATÓRIOS KNOLL}

\section{Breve histórico}

A Biblioteca da indústria farmacêutica foi criada em 1990, com o objetivo de organizar e disponibilizar as informações científicas e/ou didáticas dos produtos fabricados e comercializados pela Empresa. Trata-se de uma Biblioteca especializada na área Biomédica $\mathrm{e}$ está subordinada à Diretoria Médica-Científica. Possui um acervo constituído de livros das seguintes especialidades : Neurologia, Cardiologia, Endocrinologia, Dermatologia e Pediatria. A Biblioteca possui várias bases de dados de Pesquisas Bibliográficas, dentre as quais destacam-se Micromedex, Medline, Lilacs, Serline, OVID e Complementary \& Alternative Medicine Series. A Biblioteca também possui um convênio com a Bireme - Biblioteca Regional de Medicina do Centro Latino-Americano e do Caribe de Informação em Ciência da Saúde - o que possibilita uma maior abrangência na localização e recuperação de artigos científicos correntes.

\section{METODOLOGIA UTILIZADA}

Foram utilizadas nesta pesquisa, consultas bibliográficas de literaturas especializadas na área, aplicação de um pré-teste; de um questionário-entrevista, acompanhado de uma carta de apresentação. A utilização do método de amostragem simples de coleta de dados e o tratamento e análise de dados.

Acrescenta-se a este estudo a estrutura funcional do objeto da pesquisa como exemplo da forma adequada para leitura e apresentação verbal. Desta forma está montada a metodologia prática da construção da pesquisa.

\section{RESULTADOS DA ANÁLISE DOS DADOS}

4.1 População/Amostragem 
A pesquisa envolveu funcionários, estagiários e prestadores de serviço. $\mathrm{Na}$ impossibilidade de se estudar a população que compôs o universo da pesquisa, 600 profissionais, utilizou-se o método de amostragem simples. Dos 70 profissionais, 36 responderam ao questionário-entrevista, correspondendo a 51,4\% da amostragem.

\subsection{Instrumentação}

O questionário-entrevista é composto de 3 questões direcionadas à identificação do usuário, 3 questões direcionadas ao perfil do usuário, 7 questões direcionadas aos serviços e produtos da biblioteca, 3 questões direcionadas à identificação dos serviços e produtos, 6 questões direcionadas às falhas do SRI, 1 questão direcionada às fontes informacionais e 2 questões direcionadas ao relacionamento entre o usuário e o bibliotecário.

Pré-teste

Aplicou-se o questionário-entrevista, durante cinco dias consecutivos, a um grupo de 07 pessoas com as mesmas características da população incluída na pesquisa. $\mathrm{O}$ objetivo foi avaliar o processo de coleta e tratamento dos dados.

\subsection{Coleta de dados}

O período de aplicação do questionário-entrevista foi de 15 dias, de 15/06/01 à 29/06/01, excetuando-se sábado e domingo. Dos 70 questionários-entrevista entregues foram devolvidos 36 , que corresponde a $51,4 \%$ de retorno.

\subsection{Tratamentos dos dados}

Os dados obtidos foram trabalhados pela estatística descritiva. 


\subsection{Análise de dados}

O questionário-entrevista foi aplicado a 36 colaboradores de uma indústria farmacêutica, com faixa etária entre 20 e 60 anos. Deste total, 46\% estão na faixa etária de 20 e 30 anos; 35,1\% estão na faixa etária de 31 e 40 anos; 13,5\% estão na faixa etária de 41 e 50 anos; 2,7\% na faixa etária de 51 e 60 anos e 2,7\% não informaram a idade.

Os entrevistados localizam-se nas seguintes regiões: 46\% moram na Zona Norte; 5,4\% na Zona Sul; 43,2\% na Zona Oeste; 2,7\% no Centro e 2,7\% na Baixada Fluminense.

Todos os 36 respondentes tem o $1^{\circ}$ grau completo. Deste total, $2,7 \%$ tem o $2^{\circ}$ grau; $75,7 \%$ tem o $3^{\circ}$ grau e $21,6 \%$ tem especialização. Entre os entrevistados não existem profissionais com mestrado, doutorado e nem pós-doutorado.

Eles ocupam cargos variados na empresa e encontram-se lotados nos seguintes setores : Médico-Científico (24,31\%); Marketing (67,6\%); Recursos Humanos (5,4\%) e Industrial $(2,7 \%)$. Constatou-se que o setor de Marketing obtem o maior número de funcionários porquê seus serviços são voltados para a área Médico-científica.

A industria farmacêutica conta com um quadro de colaboradores com vínculo de trabalho entre: 1 e 5 anos (56,8\%); 6 e 10 anos (27\%); 11 e 15 anos (16,2\%).

Em relação aos serviços e produtos oferecidos pela biblioteca, 94,6\% conhecem e 5,4\% não conhecem. A maioria, 86,5\% não freqüenta outra biblioteca, restando apenas 13,5\% que freqüenta.

Dos 36 entrevistados, 83,8\% tem suas necessidades atendidas e 16,2\% não. Quanto ao atendimento pessoal, $100 \%$ concorda que a Biblioteca oferece um ótimo serviço. 
Com mais de uma opção assinalada, os índices indicam que 67,6\% dos respondentes preferem utilizar a biblioteca à tarde; $56,7 \%$ pela manhã; $10,8 \%$ não utilizam; $2,7 \%$ utilizam à noite $\mathrm{e}$ 2,7\% não tem horário definido. Quanto ao produto da busca (resultados da pesquisa), 59,4\% utilizam para atender à solicitação externa; 51,3\% para solucionar dúvidas surgidas no horário de expediente; $40,5 \%$ para atender à solicitação interna e 37,8\% para conhecimento pessoal.

Com relação ao acervo, 29,7\% procura direto na estante, sendo que 54,6\% tem facilidade para encontrar as informações desejadas e $45,4 \%$ tem relativa facilidade, $83,8 \%$ solicitam a ajuda do bibliotecário.

A idéia de biblioteca e Serviço de Recuperação da Informação (SRI), não é estranha aos entrevistados. Entretanto, a freqüência à biblioteca é relativa, pois, 13,5\% freqüentam a biblioteca diariamente; $32,4 \%$ uma vez por semana; $16,2 \%$ uma vez por mês; $16,2 \%$ raramente; $8,1 \%$ não souberam precisar; $2,7 \%$ bimestral; $2,7 \%$ trimestral; $2,7 \%$ semestral e $2,7 \%$ não freqüentam.

Um dos fatores importantes no desenvolvimento desta pesquisa, era saber o grau de conhecimento dos entrevistados com relação as ferramentas de pesquisa que a biblioteca possui. Dos 36 respondentes, $51,4 \%$ conhecem as ferramentas e 48,6\% não conhecem.

Apesar do resultado supra, 70,3\% mostra significativo interesse em pesquisar na biblioteca; $37,8 \%$ vão a biblioteca para xerocopiar material ; 21,6\% vão pegar material emprestado; 5,4\% vão estudar com o próprio material e $2,7 \%$ não responderam a pergunta. Ressalta-se que nenhum dos entrevistados utiliza a biblioteca como lugar de leitura.

Para propor o desenvolvimento de algumas mudanças no Serviço de Recuperação da Informação (SRI) da biblioteca de uma indústria farmacêutica, foi preciso saber o que pode ser melhorado na biblioteca para atender os usuários. Entre as respostas, verificou-se que: 21,6\% propôs a ampliação do espaço físico; $13,5 \%$ atualização constante do acervo; $2,7 \%$ aquisição de novas assinaturas de bases de dados; 10,8\% aumento do acervo; 2,7\% disponibilidade do acervo em rede; $8,1 \%$ marketing dos serviços; 5,4\% marketing do produtos; 
2,7\% aumento de funcionários; $2,7 \%$ melhor organização da biblioteca; $13,5 \%$ não encontram falhas no SRI e 21,6\% não responderam a questão.

Quanto à eficiência do SRI, 97,3\% responderam que conseguem a informação desejada e apenas 2,7\% não. Em relação às causas da não utilização da Biblioteca, 29,7\% responderam não ter tempo de freqüentar a biblioteca; $5,4 \%$ por freqüentar outras bibliotecas; $2,7 \% \mathrm{o}$ acervo não atender as necessidades e $62,2 \%$ não responderam a questão.

Dos entrevistados $75,7 \%$ não freqüentam outras bibliotecas e apenas $24,3 \%$ freqüentam as Bibliotecas Universitárias, a Biblioteca Nacional, a do INT(Instituto Nacional de Tecnologia). Dos $24,3 \%$ que freqüentam outras bibliotecas, $16,2 \%$ procuram bibliotecas com acervo de maior interesse; $5,4 \%$ com horários mais acessíveis e 2,7\% mais próximas de sua residência.

Quando os respondentes não encontram o material desejado, sua primeira atitude é pedir ajuda ao bibliotecário(89,2\%); procurar um material substituto (10,8\%); pedir material emprestado a outra pessoa (2,7\%); comprar o material(2,7\%); voltar depois $(2,7 \%)$ e $(2,7 \%)$ não responderam a essa questão.

Dos respondentes, $67,6 \%$ fazem consulta ao acervo de livros e solicitam o levantamento bibliográfico ao bibliotecário; $62,2 \%$ consultam o acervo de periódico; $56,7 \%$ pesquisam na Internet e solicitam artigos científicos à BIREME; 48,6\% consultam a base de dados; $45,9 \%$ xerocopiam e $8,1 \%$ utilizam o Comut bibliográfico. Dos entrevistados $97,3 \%$ recorre ao profissional da informação para fazer suas pesquisas e 2,7\% não.

Em relação à atuação dos bibliotecários, os dados revelaram que o relacionamento dos bibliotecários com os usuários fícou entre "ótimo e bom"(91,9\%); a receptividade no atendimento ficou entre "ótimo e bom"( $94,6 \%)$; a orientação quanto ao uso da biblioteca ficou entre "ótimo e bom"(89,2\%); o conhecimento do acervo ficou entre "ótimo e bom"(83, 8\%) e o auxílio às dificuldades dos usuários entre "ótimo e bom”(97,3\%). 


\section{CONSIDERAÇÕES FINAIS}

Os objetivos fixados para esta pesquisa não permitem que o assunto SRI seja tratado com a profundidade que merece. Ele é por demais amplo. Pesquisou-se o SRI da biblioteca de uma indústria farmacêutica com a pretensão de descobrir qual era a relação entre o usuário e o SRI e com a análise dos dados coletados, contribuir para a melhoria do serviço. Imaginou-se defrontar com um serviço pouco conhecido e utilizado por seus usuários. Porém, alcançou-se muito mais do que o esperado. A análise dos dados coletados mostrou um quadro bem amplo de itens positivos, traçando perfis de usuários potenciais. Proporcionou uma reflexão mais profunda sobre a importância do SRI no contexto das atividades dos profissionais de uma indústria farmacêutica, contribuindo para que eles cumpram com seus compromissos profissionais e tenham como aliados nos momentos mais difíceis, o profissional da informação. Ademais, a análise dos dados coletados confirma que todos primam pela excelência do SRI. Portanto, são incontestáveis os benefícios que o SRI trás a todos que o utiliza.

Vale lembrar, aqui, que os dados coletados foram tratados do ponto de vista da consulta ao SRI para obter uma informação eficiente, verificando o desempenho do mesmo. Entretanto, tendo como objetivo o desempenho do SRI, deve-se levar em conta a criação de um ambiente propício para o desenvolvimento do serviço, dentro da própria instituição. Ao terminar esta pesquisa, percebeu-se que ela contribuirá para corrigir algumas falhas no SRI. Traçou-se um alvo a ser atingido à espera de que o usuário possa utilizar o SRI e sinta-se satisfeito com o resultado obtido. 


\section{REFERÊNCIAS}

ASSOCIAÇÃO BRASILEIRA DE NORMAS TÉCNICAS, Rio de Janeiro. Referências bibliográficas: NBR - 6023. Rio de Janeiro, 1989. 19 p.

A BIBLIOTECA pública : administração, organização, serviços. Rio de Janeiro : DNL, 1995.

BRUNETTI, M. I. S. Proposta de uma metodologia para integrar os programas de educação de usuários aos objetivos educacionais da universidade. Campinas, 1983. 143 p. Dissertação (mestrado em Biblioteconomia) - Universidade Católica de Campinas, 1983.

CESARIO, Maria Augusta da Nobrega. Sistemas de recuperação da informação. R. Esc. Bibliotecon. UFMG, Belo Horizonte, v. 14, n. 2, p. 157-168, set. 1985.

CLANCONL, Regina de Barros. Sistemas de recuperação em linha : educação x atualização profissional. Ci. Inf., Brasília, v. 19, n. 2, p. 131-36, jul./dez. 1990.

COELHO, Beatriz Amaral de Salles, et al. Estudos de usuários e comunicação científica: Relações implícitas e explícitas. Ci. Inf., Brasília, v. 16, n. 1, p. 62-73, jan./jun. 1989.

CONCEIÇÃO, Claudia Eulina da. Perfil do usuário da biblioteca setorial do centro de ciências humanas da UNIRIO. Rio de Janeiro: [s.n.], 1999. 63 p.

DANTAS, Marcos. Sistemas de informação : a evolução dos enfoques. Ci. Inf., Brasília, v. 21, n. 3, p. 192-196, set./dez. 1992.

DAVID, Angela Pompeu. Serviços de informação em institutos de pesquisa industrial. Ci. Inf., Rio de Janeiro, v. 7, n. 2, p. 85-92, 1978.

FERREIRA, Sueli Mara Soares Pinto. Novos paradigmas e novos usuários de informação. Ci. Inf., v. 25, n. 2, 1995.

FIGUEIREDO, Nice de Menezes. Avaliações de coleções e estudo de usuários. Brasília: Associação dos Bibliotecários do Distrito Federal, 1979. 96 p.

. Estudos de uso e usuários da informação. Brasília: IBICT, 1994. 154 p.

Treinamento do usuário. Ângulo, Lorena, v. 30, n. 2/3, p. 4-5, abr./jun. 1986.

FURNIVAL, Ariadne Chloê. A participação dos usuários no desenvolvimento de sistemas de informação. Ci. Inf., Brasília, v. 25, n. 2, p. 1-18, jun. 1995. 
KNOLL A. G. e os produtos. Bilhuber-Knoll Corporation: New Jersey, [1975].

KNOLL em notícias, v. 4, n. 18, p. 1, ag./set. 1986.

LANCASTER, F.W. Information Retrieval Systems. Trad. e Coord. Hagar Espanha Gomes.2.ed. New York: John Weley \& Sons, 1979. 381 p. Cap. 1.

LIMA, Clóvis Ricardo Montenegro de. Estudos de usuários de sistemas de informação: Contribuição metodológica da epidemiologia. Ci. Inf., Brasília, v. 18, n. 2, p. 165-73, jul./dez. 1989.

MEY, Eliane Serrão Alves, MOREIRA, Maria José. Estudo de usuários da biblioteca setorial do centro de ciências humanas da UNIRIO. Rio de Janeiro, 1993. Projeto de pesquisa financiado pelo CNPQ.

PFROMIN NETO, Samuel. A biblioteca como instrumento de tecnologia educacional. R. Esc. Biblioteconomia UFMG, Belo Horizonte, v. 4, n. 1, p. 19-39, mar. 1975. p.34.

ROWLEY, Jennifer. Informática para biblioteca. Trad. Antonio Agenor Briquet de Lemos. Brasília : Briquet de Lemos/Livros, 1994. 307 p.

SILVA, Marília Motta Lugero da. Estudo de segmento de usuários da biblioteca setorial do centro de letras e artes da UNIRIO. Rio de Janeiro : UNIRIO, 1991. 75 p.

\section{ROBSON DA SILVA TEIXEIRA}

Bibliotecário da Universidade da Cidade (UniverCidade) - RJ.

Especialista em Indexação e Recuperação da Informação

Chefe do Centro de Informações Científicas da UniverCidade, unidade Santa Cruz.

Pós-graduado em Indexação e Recuperação da Informação pela Universidade Santa Úrsula (RJ).

E-mail: rteixeira@univercidade.br/robinho27850@hotmail.com

Artigo aceito para publicação em: 12/2004 